\title{
An unusual cause of spontaneous hemothorax》 Peripheral primitive neuroectodermal tumor (PNET) in chest
}

wuping Wang ( $\nabla$ wwp._8@163.com )

Xi'an Tangdu Hospital OF AFMU

Qiang Lu

Xi'an Tangdu Hospital of AFMU

Jia Ma

Xi'an Tangdu Hospital of AFMU

Tao Jiang

Xi'an Tangdu Hospital of No4 Military Medical University

Zhe Li

Yan'an people's hospital

\section{Case report}

Keywords: PNET, spontaneous hemothorax

Posted Date: January 3rd, 2020

DOl: https://doi.org/10.21203/rs.2.19934/v1

License: (c) (i) This work is licensed under a Creative Commons Attribution 4.0 International License. Read Full License 


\section{Abstract}

Background: Spontaneous hemothorax is often related with several self-diseases in the absence of history of trauma or iatrogenic injury.

Case presentation: This study aimed to report the case of a 30-year-old patient diagnosed with peripheral primitive neuroectodermal tumor (PNET) accompanied by an intra-thoracic hemorrhage as the initial and life-threatening manifestation. To our knowledge, this is the second case being reported with spontaneous hemothorax due to PNET and also the first one being reported in adult patients.

Conclusions: The clinicians should keep in mind that the PNET is one of rare cause of spontaneous hemothorax.

\section{Background}

Acute hemothorax is the sudden accumulation of blood in the pleural space, which can be caused by chest trauma, iatrogenic injury and other rare diseases [1]. As a subcategory of hemothorax, spontaneous hemothorax is much less common and often related with several self-diseases, such as spontaneous pneumothoax, vascular malformations and neoplasia in the absence of history of trauma or iatrogenic injury [1]. Here, we report an unusual case of spontaneous hemothorax associated with peripheral primitive neuroectodermal tumor (PNET).

\section{Case Presentation}

A 30-year-old male patient was admitted to the emergent room of our hospital on 26 March 2018 for sudden appearance of the right-side chest pain when get up in the morning, followed by significant breath shortness and fatigue. He had no history of trauma and iatrogenic injury. Vital signs included heart rate of 108 beats /minute, blood pressure of $80 / 55 \mathrm{mmHg}$, and a respiratory rate of 22 breaths /minute. The blood routine test showed that the hemoglobin was $6.7 \mathrm{~g} / \mathrm{dl}$. The chest computed tomography (CT) revealed right massive pleural effusion in which a high-low mixed density shadow $(11 \times 11 \mathrm{~cm} 2)$ was found (Fig. 1A). All these findings indicated a spontaneous hemothorax. Therefore, emergent surgery was performed. When we cleared away the accumulated blood of the thoracic cavity, a large tumor (about 11 centimeters in diameter) with abundant blood supply came into our eyes (Fig. 1B), and extruded the surrounding tissues. While the pedicle of the tumor located at the chest wall between the seventh to eighth ribs, and the site of hemorrhage was found in the tumor pedicle (Fig. 1B). So we sewed up the bleeding, and resected the tumor, including parts of the seventh and eighth ribs. The tumor was finally diagnosed as peripheral PNET by histopathology and immunohistochemistry (Fig. 2). The patient's postoperative course was uneventful.

\section{Discussion And Conclusions}


Haemothorax is the presence of blood in the pleural space, which can be caused by trauma, iatrogenic injury and other diseases [1]. As a subcategory of hemothorax, spontaneous hemothorax is much more rare, and sometimes caused by several self-diseases in the absence of trauma or atrogenic injury, but the data was only limited to case reports or case series [1]. We hereby report a case of spontaneous hemothorax in a patient with chest PNET who underwent an emergency thoracotomy.

PNET is an aggressive malignant tumor comprised of small round cells of putative neuroectodermal origin [2]. Occasionally, peripheral PNET was found in the thorax, affecting the ribs, sternum, scapula, clavicle and soft tissues of the chest wall and pleura [3]. The common symptom of chest PNET is the chest pain. However, with the enlargement of the tumor, chest tightness and dyspnea may occur [3]. In our case, the symptom occurs suddenly due to a life-threatening intra-thoracic hemorrhage as a result of spontaneous hemothorax. To our knowledge, there is only one case being reported with spontaneous hemothorax due to PNET in literatures [4], and our case was the second one, and also was the first one being reported in adult patients.

The mechanism of bleeding caused by PNET in chest is unclear. In our case, the bleeding may result from the nourishing vessels' injury associated with rupture of the damaged pedicle caused by the traction of tissue adhesion and long term friction between the tumor and peripheral tissues. Previous literature told us that the pneumothorax may easily occur near the lower lobe and visceral pleura as a result of lung injury caused by rib exostoses, because the respiratory motion of the lower lobe is much more significant than that of the right other lobes [5]. The cause of bleeding in our case may be explained with similar mechanism.

In conclusion, the clinicians should keep in mind that the PNET is one of rare cause of spontaneous hemothorax, although the bleeding mechanism is unclear.

\section{Declarations}

\section{Availability of data and materials}

Not applicable

\section{List of abbreviations}

PNET囚primitive neuroectodermal tumor, CT囚computed tomography

\section{Acknowledgements}

Not applicable

\section{Authors' contributions}

Wu-ping Wang analyzed and interpreted the patient data. Qiang Lu and Jie Ma were the major contributors in the writing of the manuscript. Tao Jiang and Zhe Li participated in the patient 
management. All authors read and approved the final manuscript

\section{Funding}

None

\section{Ethics approval and consent to participate}

Not applicable

\section{Consent for publication}

Present

\section{Competing interests}

The authors declare that they have no competing interests

\section{Author details}

1.Department of Thoracic Surgery, The Second Affiliated Hospital of AFMU, Air Force Medical University, 710038 , Xi'an, Shanxi ,China. 2.Department of Oncology, Yan' an people's hospital, 710060, Yan'an, Shanxi, China.

\section{References}

1.

Patrini D, Panagiotopoulos N, Pararajasingham J, Gvinianidze L, lqbal Y, Lawrence DR. Etiology and management of spontaneous haemothorax. J Thorac Dis. 2015 Mar;7(3):520-6.

2.

Gao L, Zhu Y, Shi X, Gao Z, Chen X. Peripheral primitive neuroectodermal tumors: A retrospective analysis of 89 cases and literature review. Oncol Lett. 2019 Dec;18(6):6885-90.

3.

Biswas B, Biswas B, Agarwala S, Shukla NK, Deo S, Sharma D, Thulkar S, Vishnubhatla S, Bakhshi S. Evaluation of outcome and prognostic factors in thoracic primitive neuroectodermal tumor: a study of 84 cases. Ann Thorac Surg. 2013;96:2006-14.

4.

Ghassemi A, Keikhaei B. Bilateral spontaneous hemothorax with PNET: A case report and review[J]. International Journal of Pediatrics. 2014;2(3):217-9.

5 .

Simansky DA, Paley M, Werczberger A, et al. Exostosis of a rib causing laceration of the diaphragm: diagnosis and management. Ann Thorac Surg. 1997;63:856-7. 


\section{Figures}

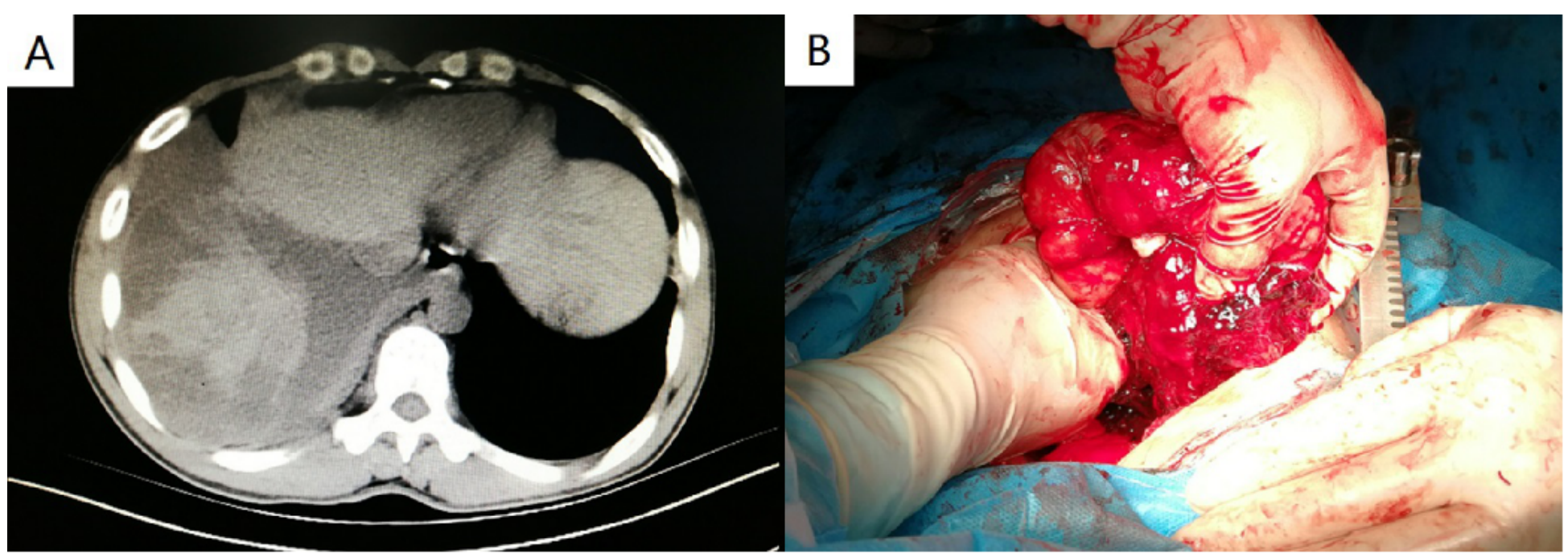

Figure 2

(A) Chest CT revealed massive pleural effusion, in which a high-low mixed density shadow $(11 \times 11 \mathrm{~cm} 2)$ was found. (B).Intraoperative exploration showed that the huge tumor located in the chest wall between the seventh to eighth ribs and the site of the hemorrhage was in the tumor pedicle.

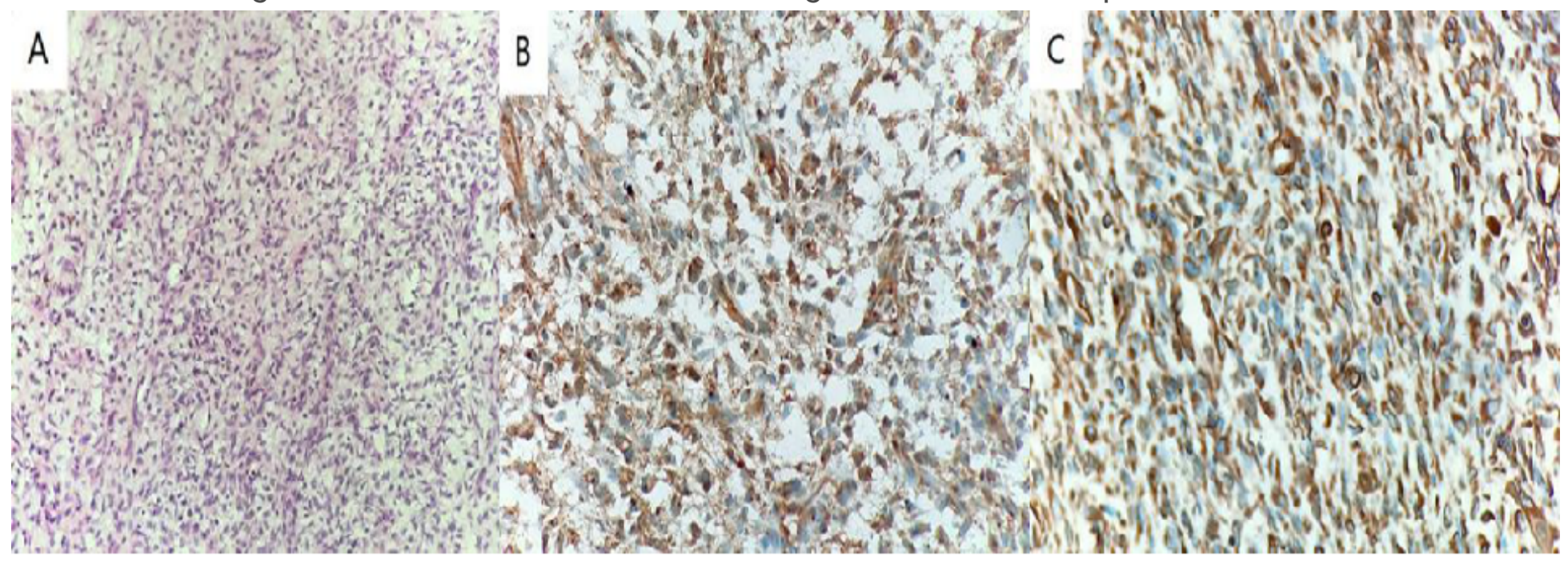

Figure 4

Histopathological (A) and immunohistochemical examination(B,C).Diffuse proliferation of small round cells with sparse clear cytoplasm is observed. The tumor cells showed intense cell-membranous immunoreactivity for MIC2 protein(CD99) (B) and Vimentin (C). 